проф., Д-р физ-мат. наук БЕЛЯЕВ Б.И. / prof. dr hab. BELIAEV B.I. ${ }^{1}$

канд. техн. наук СОСЕНКО В.A. / dr SOSENKO V.A. ${ }^{1}$

канд. техн. наук БЕЛЯЕВ Ю.В. / dr BELIAEV Y.V. ${ }^{1}$

ЧУМАКОВ А.В. / CHUMAKOV A.V. ${ }^{1}$

СИЗИКОВ А.C. / SIZIKOV A.S. ${ }^{2}$

Przyjęty/Accepted/Принята: 05.02.2014;

Zrecenzowany/Reviewed/Рецензирована: 17.03 .2014 ;

Opublikowany/Published/Опубликована: 30.06.2014;

\title{
ВОЗМОЖНОСТЬ ИСПОЛЬЗОВАНИЯ АВИАЦИОННОЙ СПЕКТРОЗОНАЛЬНОЙ СИСТЕМЫ «АВИС» ДЛЯ ДИСТАНЦИОННОГО МОНИТОРИНГА ЧС ${ }^{3}$
}

\author{
The Possibility of Using the Aviation Spectra-zone System "AVIS" \\ for the Remote Monitoring of Emergencies
}

\author{
Możliwość wykorzystania lotniczego systemu „AVIS” \\ w celu zdalnego monitorowania sytuacji nadzwyczajnych
}

\begin{abstract}
Аннотация
Цель: В статье рассматривается общее устройство, состав, основные характеристики и программное обеспечение созданного в Республике Беларусь нового образца авиационной спектрозональной системы «АВИС» высокого пространственного и спектрального разрешения с автоматическим адаптивным управлением, а также приводятся некоторые результаты проведенных летных испытаний.

Введение: В рамках реализации ГНТП «Космические системы и технологии» Национальной программы исследования и использования космического пространства в мирных целях создана авиационная спектрозональная система «АВИС» высокого пространственного и спектрального разрешения с автоматическим адаптивным управлением как составная часть системы многоуровневого авиакосмического мониторинга территорий Республики Беларусь. Разработаны методы ее калибровки, методики измерения параметров различных объектов и сред, а также программы управления работой системы. Основным назначением «АВИС» является регистрация спектрозональных и тепловых изображений земной поверхности. Система «АВИС» предусмотрена для эксплуатации на самолете АН-2 МЧС Республики Беларусь, оборудованном специальным иллюминатором, и устанавливается на гироплатформу, чтобы компенсировать нестабильность полета носителя. Система состоит из блока оптических датчиков (БОД), рабочей станции (РС) и комплекта визуального позиционирования (КВП). С целью управления и регистрации данных, получаемых модулями БОД, был разработан специальный программный комплекс, учитывающий особенности аппаратного интерфейса. В состав данного программного обеспечения входят пять модулей.

Выводы: В июне 2012 г. успешно были проведены летные испытания экспериментального образца (ЭО) «АВИС» на борту самолета АН-2 Витебского филиала ГП «Беллесавиа» МЧС РБ. Монтаж модулей и блоков системы «АВИС» на борту самолета осуществлялся в полевых условиях на полевом аэродроме. Съемки проводились с высот 1000, 700, 600 и 300 м. Площадные съемки проведены в результате полета по параллельным маршрутам методом «параллельное галсирование» с высоты 1000 м. Время полета составило 1 час 50 минут. В результате летных испытаний ЭО «АВИС» показал устойчивость к воздействию механических нагрузок при взлете и посадке самолета АН-2 с грунтового аэродрома. По результатам обработки и анализа данных съемок построены трассовые (линейные) и площадные мозаики районов съемок, получены твердые копии спектрозональных и тепловых изображений районов съемок, проведены оценки точности определения площадей в видимом и ИК диапазоне.
\end{abstract}

\footnotetext{
${ }^{1}$ Научно-исследовательское учреждение «Институт прикладных физических проблем имени А.Н. Севченко» БГУ, Минск, Республика Беларусь, электронная почта: remsens@mail.ru /Institute of Applied Physical Problems of A.N. Sevchenko of Belarus State University, e-mail address: remsens@mail.ru;

2 Учреждение «Научно-исследовательский институт пожарной безопасности и проблем чрезвычайных ситуаций» Министерства по чрезвычайным ситуациям Республики Беларусь, г. Минск, ул. Солтыса, 183a; электронная почта: niipb@anitex.by / The Establishment «Research Institute of Fire Safety and Emergencies» of the Ministry for Emergency Situations of the Republic of Belarus, Minsk, Soltisa str, 183a; e-mail address: niipb@anitex.by;

${ }^{3}$ Авторы внесли одинаковый вклад в статью / The authors contributed equally to this work
} 
Значение для практики: Применительно к деятельности МЧС Республики Беларусь, разработанная система «АВИС» позволяет: обеспечивать оперативное построение картосхем тепловых полей лесных и торфяных пожаров в условиях сильной задымленности; определять масштабы утечек из нефте- и продуктопроводов, оценивать их последствия; строить картосхемы затопленных территорий и повреждений от ураганов; строить профили тепловых полей продуктопроводов, тепловых трасс жилых районов и промышленных объектов; оценивать повреждения, нанесенные сельскохозяйственным культурам природными факторами (заморозки, засуха, подтопление и др.).

Ключевые слова: авиакосмический мониторинг, спектрозональная система, чрезвычайные ситуации, спектрорадиометр, тепловые изображения

Вид статьи: с практики для практики

\begin{abstract}
Objective. The article describes general structure, main characteristics and the software of a new model of the aviation spectra-zone system called "AVIS". The system was created in The Republic of Belarus. It is characterized by high spatial and spectral resolution and automatic adaptive control system. The article also presents some flight tests results.

Introduction: The aviation high spatial and spectral resolution spectra-zone system "AVIS" with automatic adaptive control is an integral part of the Multilevel aerospace territory monitoring system of the Republic of Belarus, created in the framework of realization of the State Scientific and Technical Programme "Space systems and technologies" of the National Programme for the exploration and using of outer space for peaceful purposes.

The calibration methods, measuring techniques of different objects and environments, as well as the software for the system management were developed. The main purpose of "AVIS" consists in the registration of spectra-zone and thermal images of the Earth surface. The "AVIS" system is designed for the operation on the AN-2 plane of the Ministry for Emergency Situations of the Republic of Belarus equipped with a special illuminator. This system is installed on the gyroscopic platform in order to reduce the instability of the plane's flight. The system consists of the block of optical sensors (BOS), workstation (W) and a set of visual positioning (SoVP). A special complex of programmes with the features of the hardware interface was developed with the purpose of registration and control of the data received by BOS modules. Five modules are included in this software.

Conclusions. The flight tests of an experimental model (EM) "AVIS" on the board of AN-2 of the Vitebsk branch of the SOE "Bellesavia" of the Ministry for Emergency Situations of the Republic of Belarus were successfully conducted in June 2012. The modules and blocks of the "AVIS" system were installed on the board of the aircraft at the airfield. The survey was conducted at the heights of 1000, 700, 600 and $300 \mathrm{~m}$. The aerial survey was conducted as a result of a flight along parallel paths - method called "parallel upwind sailing", at the height of $1000 \mathrm{~m}$. The flight took 1 hour and 50 minutes. The EM "AVIS" showed resistance to the impacts of mechanical loads during takeoff and landing of AN-2 at the soil airfield. On the basis of processing and analysis of these pictures, trace (linear) and areal mosaics of the examined territory were prepared. What is more, hard copies of spectra-zone and thermal images of the examined area were obtained. The researchers estimated the accuracy of the determination of areas in the visible and IR range.

Implications for practice. In the context of the activity of the Ministry for Emergency Situations of the Republic of Belarus, the developed system "AVIS" allows: to provide executive construction of the schematic maps of the thermal fields of forest and peat fires in heavy smoke; to determine the scale and leaks from oil and product pipelines; to evaluate their consequences; to construct the schematic maps of the flooded areas and damage from hurricanes; to construct profiles of thermal fields of product pipelines, thermal paths of residential areas and industrial facilities; to evaluate the damage to crops by natural factors (frost, drought, flooding, etc.).
\end{abstract}

Key words: aerospace monitoring, spectra-zonal system, emergencies, spectroradiometer, thermal images

Type of article: best practice in action

\title{
Abstrakt
}

Cel: W artykule opisano ogólną konstrukcję, budowę, główne cechy i oprogramowanie komputerowe opracowanego w Republice Białorusi nowego modelu systemu „AVIS” o dużej rozdzielczości przestrzennej i spektralnej, wykorzystującego układ sterowania automatycznego. Co więcej w artykule opisano część wyników uzyskanych z przeprowadzonych badań lotniczych.

Wprowadzenie: W ramach realizacji państwowego naukowo-technicznego programu „Systemy i technologie kosmiczne” krajowego programu badań i wykorzystania przestrzeni kosmicznej w celach pokojowych opracowano system fotografii lotniczej „AVIS” o dużej rozdzielczości przestrzennej i spektralnej, wykorzystujący adaptacyjny układ sterowania automatycznego. System stanowi integralną część wielopoziomowego lotniczo-kosmicznego systemu monitorowania terytorium Republiki Białorusi. Opracowane zostały metody jego kalibrowania, metody pomiarowe parametrów różnych obiektów i środowisk, a także programy sterowania pracą systemu. Podstawowym przeznaczeniem „AVIS” jest rejestrowanie spektralnych i termowizyjnych obrazów powierzchni Ziemi. System „AVIS” przewidziany jest do użytkowania na pokładzie samolotu AN-2 Ministerstwa Sytuacji Nadzwyczajnych Republiki Białorusi, wyposażonego w specjalny iluminator. System umieszczany jest na żyroskopowej platformie, aby zrównoważyć niestabilność lotu nośnika. Składa się z bloku czujek optycznych, stacji roboczej i systemu pozycjonowania optycznego. Aby zarządzać danymi przekazywanymi z modułów czujników i je rejestrować, opracowano specjalny kompleks programowy uwzględniający specyfikę interfejsu aparatury. W skład danego oprogramowania wchodzi pięć modułów.

Wnioski: W czerwcu 2012 roku z powodzeniem przeprowadzono badania lotnicze modelu eksperymentalnego „AVIS" na pokładzie samolotu AN-2 Oddziału w Vitebsku Organizacji państwowej „Bellesavia” Ministerstwa sytuacji nadzwyczajnych Republiki Białorusi. Montaż modułów i bloków systemu „AVIS” na pokładzie samolotu przeprowadzono na lotnisku polowym. Zdjęcia były wykonywane na wysokości 1000, 700, 600 i 300 metrów. Zdjęciaterenowe zrobiono w czasie lotu po równoległych trasach metodą „halsowania równoległego” z wysokości 1000 metrów. Czas lotu wyniósł godzinę 50 minut. W rezultacie badań lotniczych „AVIS” wykazał odporność na oddziaływanie obciążenia mechanicznego przy starcie i lądowaniu samolotu AN-2 z lotniska gruntowego. Na podstawie wyników obróbki i analizy danych zdjęć opracowano liniowe i obszarowe mozaiki rejonów zdjęć. Otrzymano wydrukowane kopie spektralnych i termowizyjnych (cieplnych) obrazów z rejonu zdjęć oraz przeprowadzono ocenę dokładności opisania badanej powierzchni w zakresie widzialnym i podczerwieni. 
Znaczenie dla praktyki: W efekcie działalności Ministerstwa ds. sytuacji nadzwyczajnych Republiki Białorusi, opracowany system „AVIS” pozwala na: zapewnienie w celach operacyjnych generowania schematów map obszarów cieplnych pożarów lasów i torfowisk w warunkach znacznego zadymienia; określanie skali wycieków z rurociąów ropy i innych, ocenianie ich skutków; generowanie schematów map zatopionych obszarów i uszkodzeń od huraganów; generowanie profilów obszarów cieplnych rurociagów, tras cieplnych na terenach mieszkalnych i obiektach przemysłowych, ocenianie strat w uprawach rolniczych wywołanych czynnikami natury (przymrozki, susze, powodzie itp.).

Słowa kluczowe: monitoring aerokosmiczny, system spektrostrefowy, sytuacje nadzwyczajne, spektroradiometr, zdjęcia termowizyjne Typ artykułu: z praktyki dla praktyki

\section{1. Введение}

На сегодняшний день при осуществлении авиационного мониторинга ЧС различного характера достаточно широко используются технические средства оптического дистанционного зонирования земной поверхности, причем как за рубежом, так и в Республике Беларусь [1-2]. В частности, для реализации данных задач НИИПФП им. А.Н. Севченко БГУ совместно с Министерством по чрезвычайным ситуациям и Министерством лесного хозяйства Республики Беларусь в рамках выполнения государственных научно-технических программ (ГНТП) был создан и внедрен в эксплуатацию ряд отечественных образцов систем авиационного мониторинга. В их числе следует особо отметить комплекс ВСК-2 (эксплуатируемый на борту вертолета Ми-2) [3-4] и авиационную систему контроля чрезвычайных ситуаций АСК-ЧС (эксплуатируемую на борту самолета Ан-2) [5-8].

С учетом растущих потребностей, развития и совершенствования научных технологий в рамках реа- лизации ГНТП «Космические системы и технологии» Национальной программы исследования и использования космического пространства в мирных целях создана авиационная спектрозональная система «АВИС» высокого пространственного и спектрального разрешения с автоматическим адаптивным управлением как составная часть системы многоуровневого авиакосмического мониторинга территорий Республики Беларусь. Разработаны методы ее калибровки, методики измерения параметров различных объектов и сред, а также программное обеспечение для управления работой системы [9].

\section{2. Основные показатели, назначение и элементы авиационной спектрозо- нальной системы «АВИС»}

Авиационная спектрозональная система «АВИС» по своим характеристикам превосходит существующие зарубежные аналоги и при этом, что особенно важно, на порядок дешевле (табл. 1).

Значения характеристик «АВИС» в сравнении с аналогами

Таблица 1.

Table 1.

The values of the characteristics of the «AVIS» in comparison with analogues

\begin{tabular}{|c|c|c|c|c|}
\hline \multirow[b]{2}{*}{$\begin{array}{c}\text { Наименования технико- } \\
\text { экономических показателей, } \\
\text { лимитная цена единицы изделия } \\
\text { / Name of technical and economic } \\
\text { indicators, the limit price per item }\end{array}$} & \multirow[b]{2}{*}{$\begin{array}{c}\text { Единица } \\
\text { измерения } \\
\text { / Unit of } \\
\text { measurement }\end{array}$} & \multicolumn{3}{|c|}{ Значение показателей/ Indicator values } \\
\hline & & $\begin{array}{c}\text { Авиационной } \\
\text { спектрозональной } \\
\text { системы АВИС / } \\
\text { Aviation spectra- } \\
\text { zonal system «AVIS» }\end{array}$ & $\begin{array}{c}\text { Лучшего } \\
\text { отечественного } \\
\text { образца: АСК- } \\
\text { ЧС / The best } \\
\text { national sample: } \\
\text { АСК-ЧС }\end{array}$ & $\begin{array}{c}\text { Лучшего зарубежного } \\
\text { аналога: UltraCamD } \\
\text { компании Vexcel Imaging } \\
\text { (Австрия) / Best foreign } \\
\text { analogue: UltraCamD } \\
\text { company Vexcel Imaging } \\
\text { (Austria) }\end{array}$ \\
\hline Высота съемки/ Survey altitude & $\mathrm{M} / \mathrm{m}$ & $500-3000$ & $500-1500$ & $500-1500$ \\
\hline $\begin{array}{l}\text { Пространственное разрешение } \\
\text { кадра/ Space resolution of cadre }\end{array}$ & $\mathrm{cm} / \mathrm{cm}$ & $5-30$ & $20-50$ & $5-20$ \\
\hline $\begin{array}{c}\text { Число элементов в полосе } \\
\text { панхроматической съемки/ } \\
\text { The number of elements in the zone } \\
\text { of the panchromatic survey }\end{array}$ & пиксель/ pixel & $\begin{array}{c}18000 \text { (плановая } \\
\text { съемка/plane } \\
\text { surveying) }\end{array}$ & 2500 & 11500 \\
\hline $\begin{array}{c}\text { Размер спектрозонального } \\
\text { изображения/ The size of the } \\
\text { spectrozonal image }\end{array}$ & пиксель/pixel & $6665 \times 4990$ & $3456 \times 2304$ & $3680 \times 2400$ \\
\hline $\begin{array}{c}\text { Поле обзора с высоты } 1 \mathrm{kм} / \text { Field of } \\
\text { view from a height of } 1 \mathrm{~km}\end{array}$ & $\mathrm{M} / \mathrm{m}$ & $\begin{array}{l}1800 \text { x } 500 \text { (плановая } \\
\text { съемка/ plane } \\
\text { surveying) }\end{array}$ & $\begin{array}{l}1250 \times 940 \\
(\mathrm{MOC})\end{array}$ & $\begin{array}{c}1150 \text { x } 750 \text { (плановая } \\
\text { съемка/plane surveying) }\end{array}$ \\
\hline $\begin{array}{l}\text { Число спектральных каналов/ } \\
\text { The number of spectral channels }\end{array}$ & шт/pcs & 12 & 9 & 4 \\
\hline $\begin{array}{l}\text { Наличие спектрорадиметра/ } \\
\text { The presence of the spectroradiometer }\end{array}$ & мкм/micron & $0,35-1,05$ & нет & нет \\
\hline $\begin{array}{c}\text { Наличие ИК-канала/ The presence } \\
\text { of the infrared channel }\end{array}$ & мкм/micron & $7,5-13$ & $7,5-13$ & нет \\
\hline $\begin{array}{l}\text { Ориентировочная стоимость/ } \\
\text { Estimated cost }\end{array}$ & USD/USD & 400000 & 150000 & 1500000 \\
\hline
\end{tabular}


Основным назначением авиационной спектрозональной системы «АВИС» является регистрация спектрозональных и тепловых изображений земной поверхности.

Применительно к деятельности МЧС Республики Беларусь, разработанная система «АВИС» позволяет:

- обеспечивать оперативное построение картосхем тепловых полей лесных и торфяных пожаров в условиях сильной задымленности;

- определять масштабы утечек из нефте- и продуктопроводов, оценивать их последствия;

- строить карто

- схемы затопленных территорий и повреждений от ураганов;

- строить профили тепловых полей продуктопроводов, тепловых трасс жилых районов и промышленных объектов;

- оценивать повреждения, нанесенные сельскохозяйственным культурам природными факторами (заморозки, засуха, подтопление и др.).

Система состоит из блока оптических датчиков (БОД), рабочей станции (РС) и комплекта визуального позиционирования (КВП).

БОД предназначен для сбора информации в видимом и инфракрасном (ИК) диапазонах длин волн. Блок состоит из пяти модулей:

- модуля спектрозонального видеонаблюдения (МСB);

- модуля спектрорадиометра (МС);

- модуля инфракрасной камеры (МИК);

- модуля лазерного высотомера (МЛВ);

- модуля обзорной камеры оператора (МОКО).

Модуль спектрозонального видеонаблюдения (МСВ) (рис. 1 а, б), состоит из трех монохромных матриц DALSA FTF5066M разрешением $4992 \times 6668$ пикселей и трех комплектов сменных объективов HASSELBLAD HC 2.8/80 и HASSELBLAD HCD 4/28. Он предназначен для получения изображений высокого и среднего пространственного разрешения раздельно в трех каналах со сменными светофильтрами, с возможностью обработки данных и получения синтезированных изображений на базе трех цифровых монохроматических матриц.

Основным назначением модуля спектрорадиометра (MC) на область 400-900 нм является управление МСВ и получения спектров высокого разрешения [10, 11] (Рис. 2 а, б, в).

Модуль инфракрасной камеры (МИК) (рис. 3) представляет собой инфракрасную камеру FLIR A650. Он предназначен для регистрации тепловых полей в ИК области спектра $8 \div 13$ мкм.

Основным назначением модуля лазерного высотомера (МЛВ) на базе лазерного дальномера «Зенит-ЛД» (рис. 4) является точное определение высоты носителя над поверхностью во время съемок и запись этих данных в блок служебной информации PC.
Модуль обзорной камеры оператора (МОКО) представляет собой цветную цифровую видеокамеру CCTV IP Camera - YUC-H696 (рис. 5).

В рабочую станцию (рис. 6) входят:

- источник питания для подачи напряжения на модули «АВИС»;

- компьютер-сервер для управления модулями БОД и платами захвата изображения;

- три платы захвата изображений;

- монитор с клавиатурой;

- GPS-приемник.

Питание РС осуществляется от бортовой сети авианосителя 27 В постоянного тока.
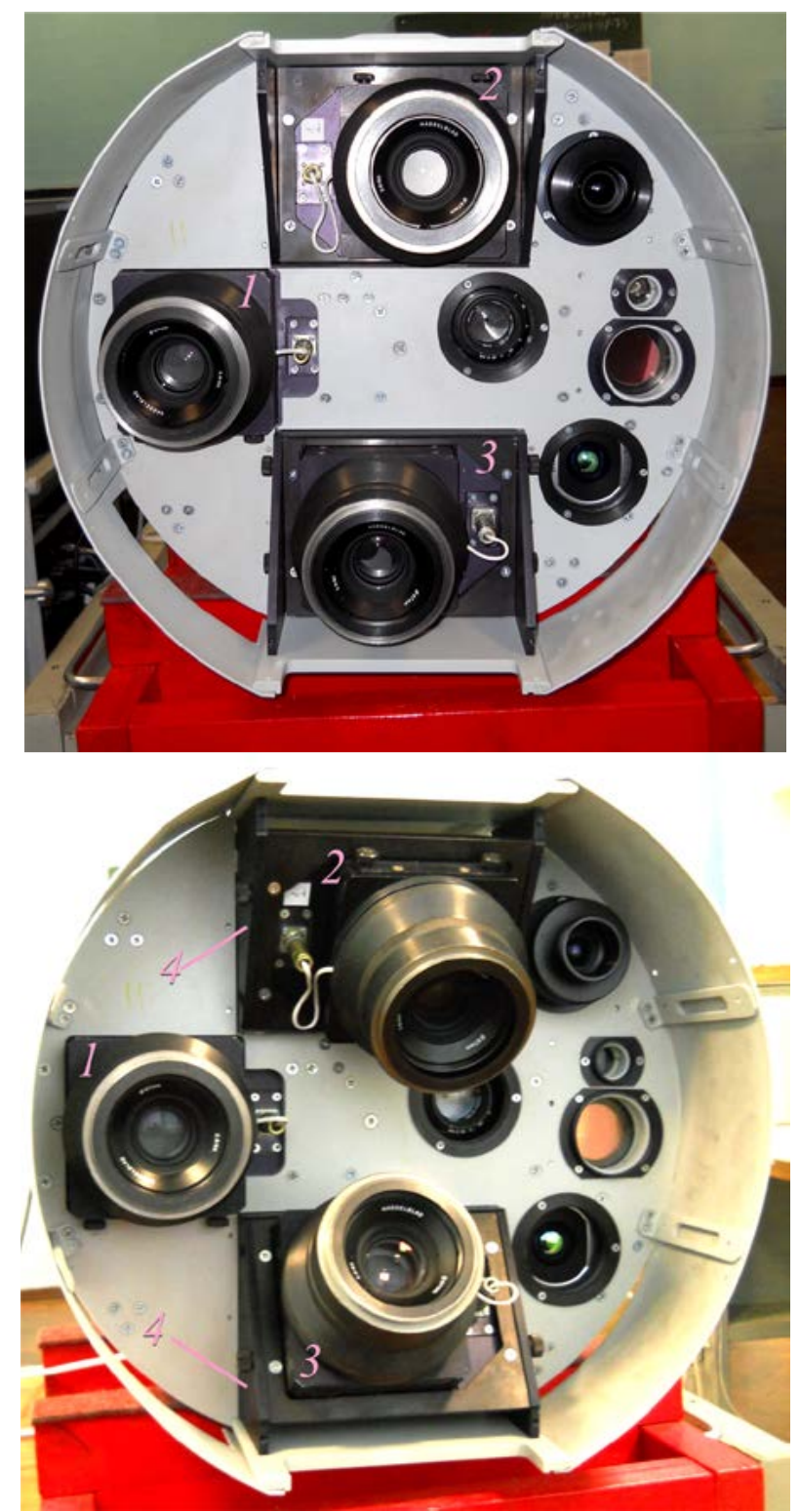

Рис. 1 а, б. Модуль спектрозонального видеонаблюдения МСB:

1, 2, 3 - съемочные камеры; 4 - устройства позиционирования камер

Fig. 1 a, b. The spectrozonal module for surveillance SMS: 1, 2, 3 - cameras; 4 - cameras location attachment 


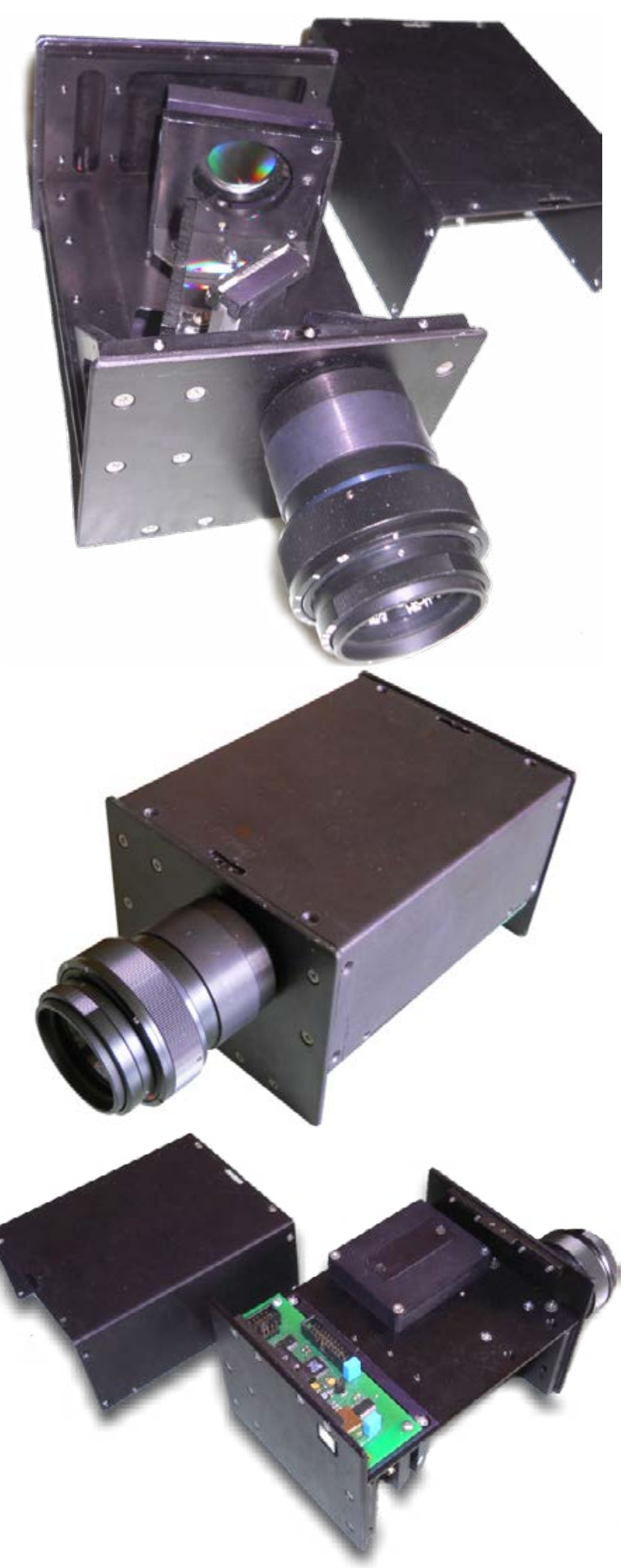

Рис. 2a, б, в. Спектрорадиометр МC - 14 Fig. 2 a, b, c. Spectroradiometer MS - 14

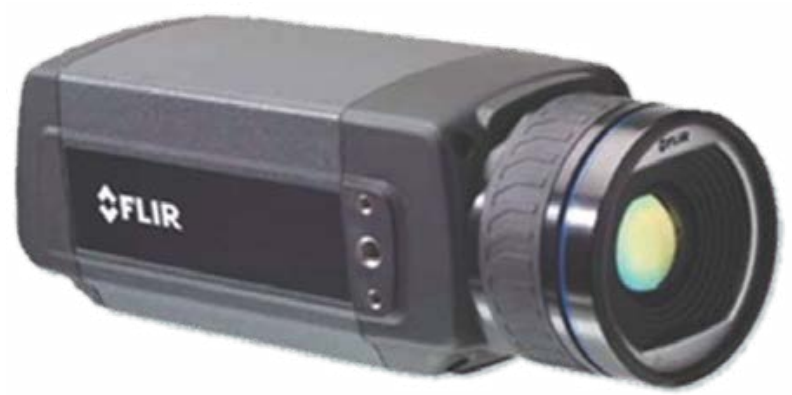

Рис.3. Инфракрасная камера FLIR A650

Fig. 3. Infrared camera FLIR A650

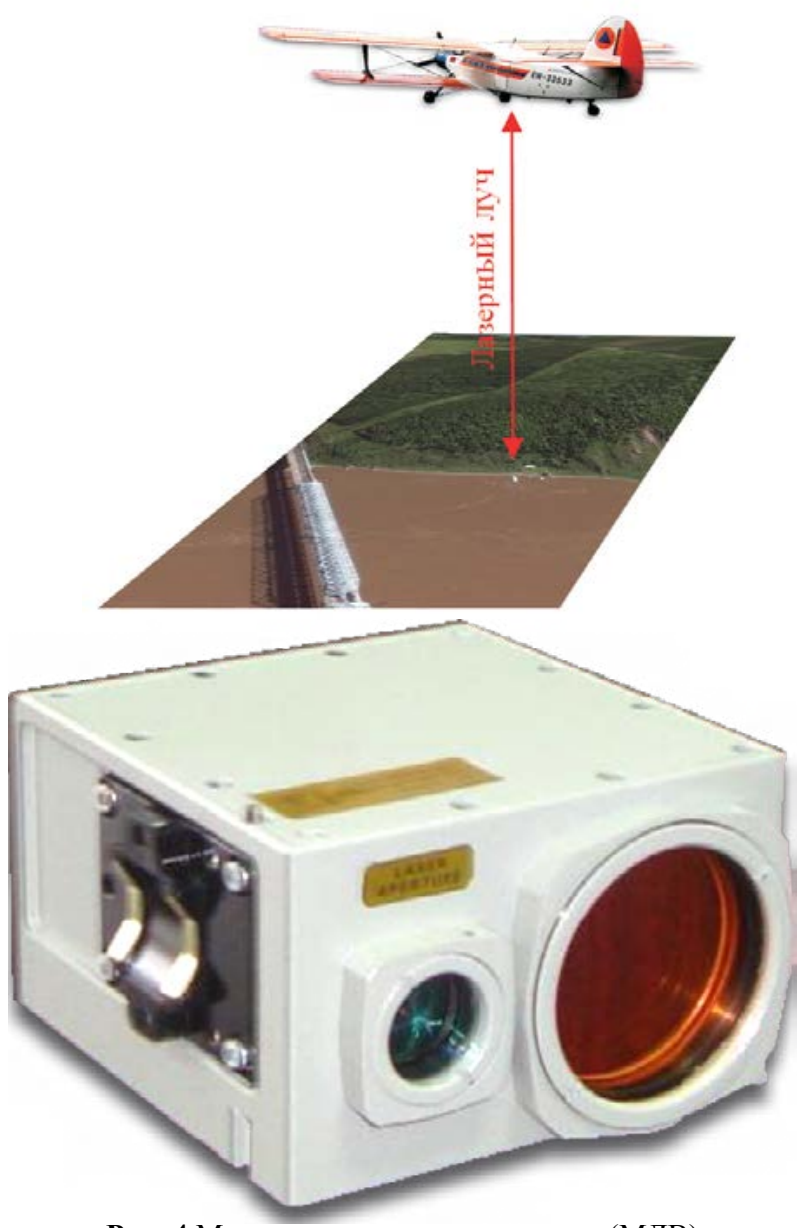

Рис. 4 Модуль лазерного высотомера (МЛВ)

Fig. 4. The module of the laser altimeter (MLA)

Возможность использования сменных объективов камер МСВ позволяет изменять пространственное разрешение и полосы съемки «АВИС» в зависимости от конкретных решаемых задач. Также, между объективами и приемными матрицами камер расположены выдвижные кассеты, что обеспечивает оперативную замену необходимого светофильтра.

МСB обеспечивает изменение углов установки съемочных камер на фиксированный угол для выполнения съемочных работ с широкой полосой захвата и при стереосъемке.

При осуществлении спектрозональной съемки все три камеры (1,2 и 3) устанавливаются в одной плоскости за счет их прилегания к базовой пластине МСB, к которой съемочные камеры притянуты крепежными невыпадающими винтами (рис. 1 а). Для установки камер в положение широкозахватной полосы съемки и при стереосъемке одна съемочная камера (1) сохраняет свое положение, а две другие (2 и 3) устанавливаются под углами $\pm 30^{\circ}$ относительно положения надира с помощью устройства позиционирования камер MCB (4) и фиксируются в этом положении (рис. 1 б). Жесткая взаимная фиксация камер, знание точных параметров их взаимного ориентирования и фокусных расстояний объективов позволяют во всех конфигурациях осуществлять аналитический переход к синтезированному снимку в единой системе координат. 


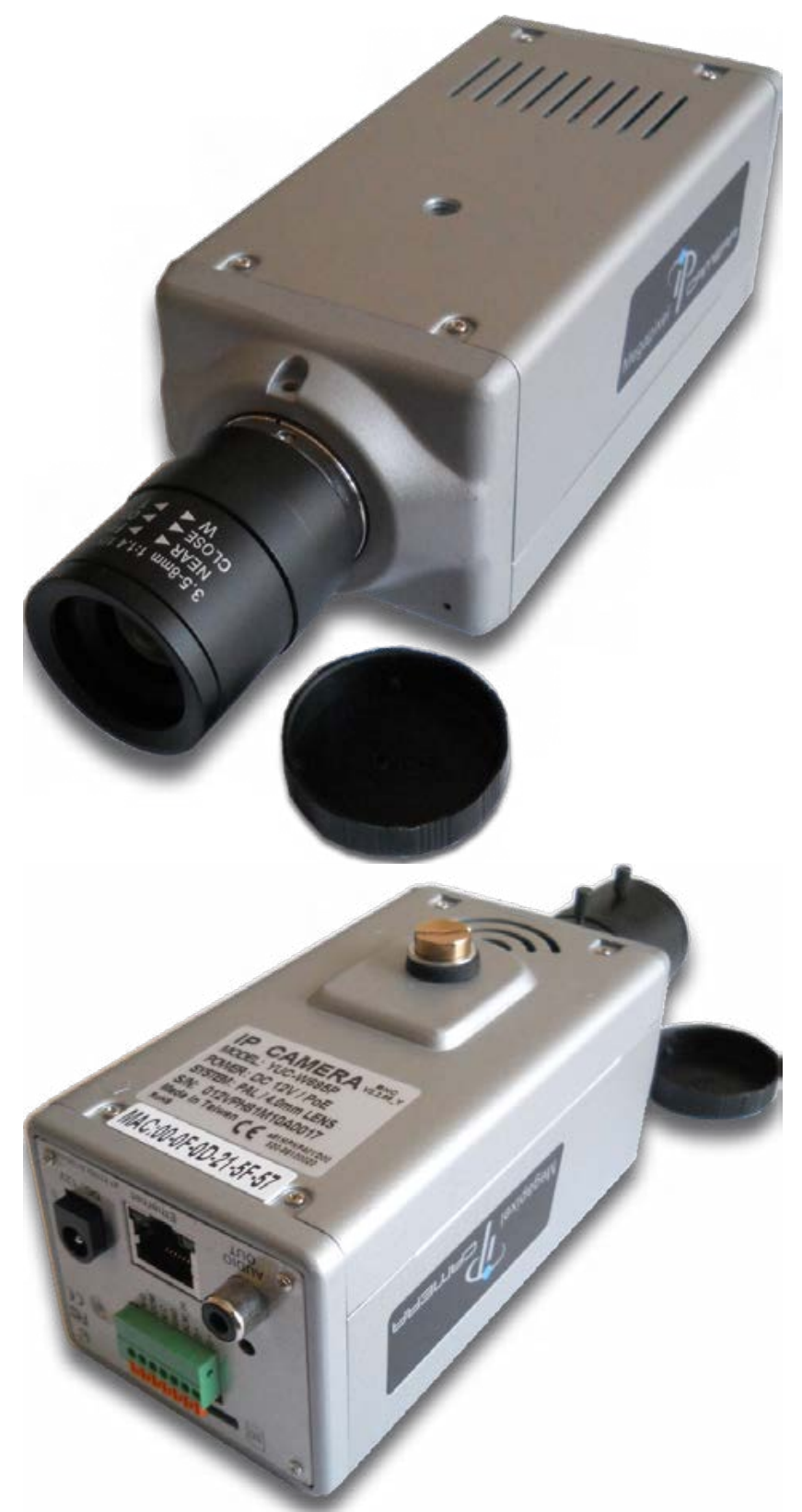

Рис. 5. Цветная цифровая видеокамера CCTV IP Camera - YUC-H696

Fig. 5. Color digital video camera CCTV IP Camera YUC-H696

Рабочая станция предназначена для управления БОД, приема и записи данных блока. РС строится на базе промышленной платформы стандарта PICMG 1.3 .

Основным назначением КВП является визуальное позиционирование летно-съемочных работ, для облегчения «захода» на съемку и контроля полета в определенном коридоре движения. КВП состоит из обзорной телевизионной камеры и монитора пилота.

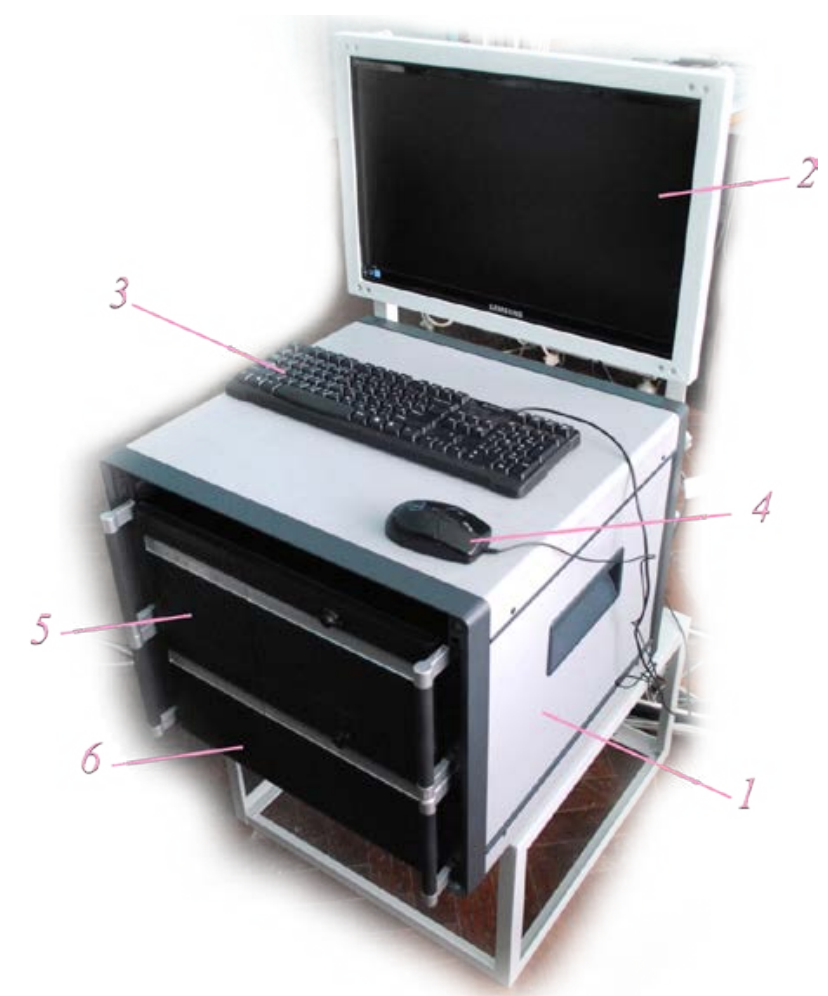

Рис. 6. Рабочая станция «АВИС»:

1 - системный блок; 2 - монитор оператора;

3 - клавиатура; 4 - «мышь»; 5 - корпус блока 1 ; 6 - корпус блока 2

Fig. 6. Workstation «AVIS»:

1 - system unit; 2 - monitor of the operator; 3 - keyboard; 4 - «mouse»; 5 - case $1 ; 6$ - case 2

\section{3. Программный комплекс управления авиационной} спектрозональной системой «АВИС»

$\mathrm{C}$ целью управления и регистрации данных, получаемых модулями БОД, был разработан специальный программный комплекс (рис. 7, 8). Он учитывает особенности аппаратного интерфейса, при помощи которого производится управление каждым из модулей, a именно двух Ethernet соединений для обзорной камеры оператора и ИК камеры, СОМ порта для управления лазерным высотомером, трех интерфейсов Camera link для управления датчиками модуля спектрозонального видеонаблюдения и одного USB coединения для управления спектрорадиометром МC-14. В состав данного программного обеспечения входят пять модулей:

- модуль управления датчиками спектрозональных изображений;

- модуль управления спектрорадиометром;

- модуль управления инфракрасной камерой;

- модуль управления лазерным высотомером;

- модуль управления обзорной камерой оператора. 


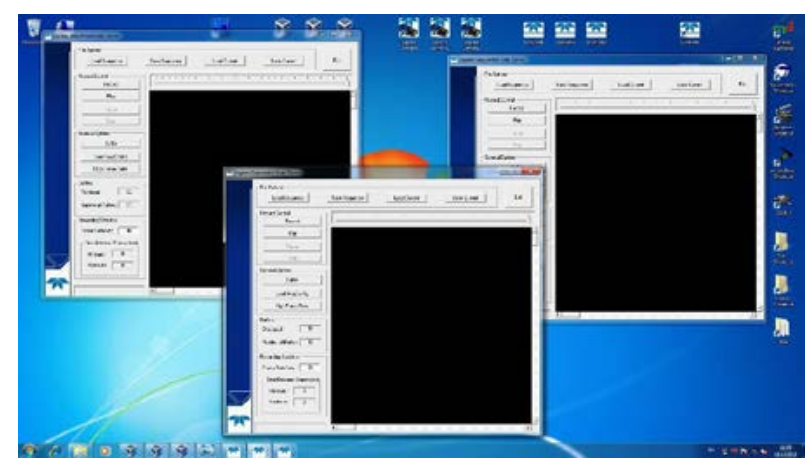

Рис. 7. Программы регистрации данных спектрозональных камер МСВ БОД АВИС

Fig. 7. The program for registration of spectrozonal cameras data MSVS BOS AVIS

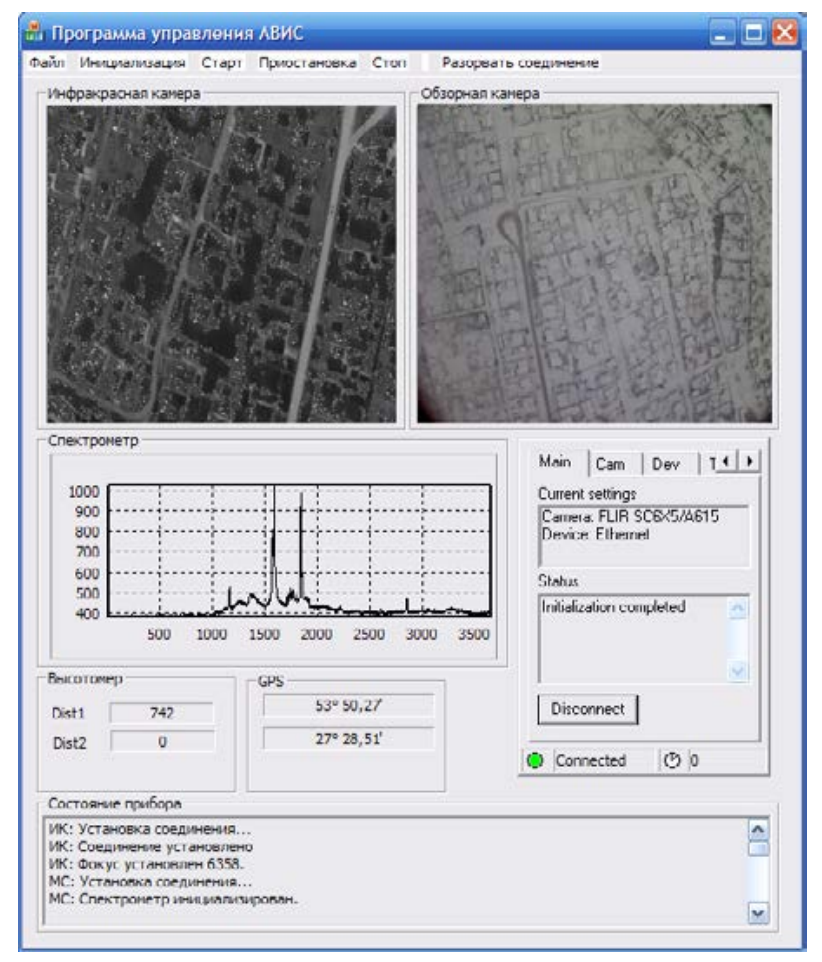

Рис. 8. Программа тестирования и управления MC, МИК, МЛВ, МСК и GPS

Fig. 8. The program for testing and control of MS, MISC, MLA, MSC and GPS

С целью регистрации монохроматического изображения с максимальным разрешением 33M active pixels (5040x6726x14 bit) был применён комплект DALSA sensor evaluation kit EK FTF5066, представляющий собой высокочувствительную ПЗС-матрицу с широким (70dB) динамическим диапазоном, модуль управления матрицей и управляющее ПО компании DALSA. Сенсор данного типа является одним из лидеров среди аналогов по уровню чувствительности, динамическому диапазону и шумовым характеристикам.

Данный комплект оборудования, по сути, не является полноценной видеокамерой, а представляет лишь её регистрирующий электронный компонент. По этой причине в процессе его встраивания в систему АВИС пришлось решать ряд технологических проблем. Был разработан и изготовлен кронштейн для размещения сенсора и объектива Hasselblad серии H-system: фактически - тело камеры. Кроме того, для управления встроенным затвором данного типа объективов был сконструирован и изготовлен модуль управления, позволяющий контролировать время открытия затвора вплоть до $2 \mathrm{~ms}$, синхронно с экспонированием сенсоpa. На базе ПО средств разработчика Sapera SDK компании Dalsa были разработаны программные средства управления сконструированной видеокамерой, контролирующие время открытия затвора, экспозицию ПЗС-матрицы, характер съёмки (серия, одиночные кадры) и ряд сервисных функций, включающих в себя коррекцию чувствительности матрицы и учёт темновых токов.

С целью регистрации спектральных данных подстилающих поверхностей был создан модуль управления спектрорадиометром, который позволяет автоматически подбирать время накопления сигнала (экспозицию), частоту получения спектров спектрорадиометром МC-14 и осуществляет запись зарегистрированных спектров в файл. Автоматический подбор времени накопления необходим для установления такой экспозиции, которая обеспечивает получение наиболее информативного спектра энергетической яркости при текущем уровне освещения подстилающей поверхности. Для этого вначале производится регистрация спектра на минимальной экспозиции, затем определяется максимальный уровень сигнала этого спектра, после чего по таблице соотношения уровня сигнала на минимальной экспозиции и соответствующей ей максимально информативной определяется подходящее время накопления. С учетом данного значения максимального уровня сигнала аналогично производится и установка времени накопления сигнала датчиков модуля спектрозонального видеонаблюдения в различных спектральных интервалах, определяемых интерференционными светофильтрами. Таким образом, спектрорадиометр выполняет две функции: регистора спектра подстилающей поверхности и экспонометра.

Основным назначением модуля управления инфракрасной камерой является установка частоты получения кадров и запись данных в файл температурных таблиц и в файл данных. Каждый кадр представляет собой псевдоизображение размерностью 16 бит и разрешением 640×480 пикселей, значения пикселей которого соответствуют номеру ячейки температурной таблицы, позволяющей в дальнейшем определить температуру в Кельвинах каждого пикселя. Каждый кадр соотносится со своей температурной таблицей. Температурная таблица получается автоматически в следующих случаях: при запуске регистрации, при возобновлении регистрации после приостановки и по истечении 10 мин после последнего получения.

Модуль управления лазерным высотомером регистрирует расстояния до ближайшей и наиболее удаленной точек и записывает эти значения в файл. Модуль управления обзорной камерой оператора устанавливает частоту кадров и записывает получаемые изображения в файл покадрово. 
Порядок записи данных для каждого модуля одинаков: сначала записывается заголовок со служебными данными, затем - время получения данных, после чего производится непосредственная запись данных. По времени записи можно произвести совмещение данных полученных в каждом из модулей.

\section{4. Летные испытания}

Система «АВИС» предусмотрена для эксплуатации на борту самолета АН-2 МЧС Республики Беларусь, оборудованного специальным иллюминатором. Для компенсации нестабильности полета носителя система монтируется на гироплатформу.

В июне 2012 г. был организован и успешно проведен комплекс летных испытаний экспериментального образца (ЭО) «АВИС» на борту самолета АН-2 Витебского филиала ГП «Беллесавиа» МЧС Республики Беларусь.

Монтаж модулей и блоков системы «АВИС» на борту самолета (рис. 9) осуществлялся в полевых условиях на полевом аэродроме.

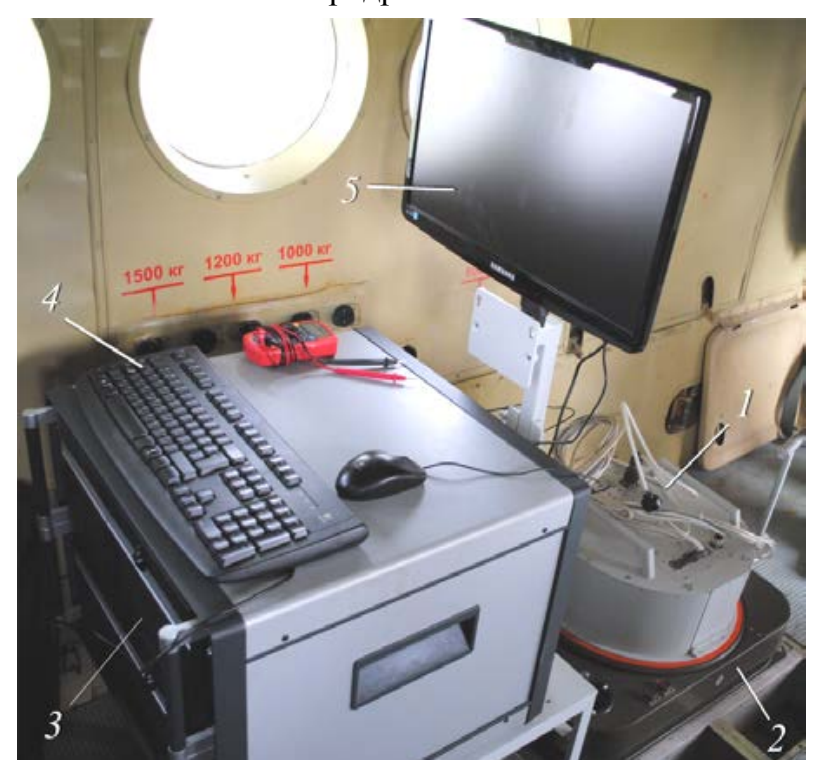

Рис. 9. Система АВИС, установленная на борту самолета АН-2:

1 - блок оптических датчиков; 2 - гироплатформа PAV-20;

3 - рабочая станция РС ; 4 - клавиатура PC; 5 - монитор РС

Fig. 9. The AVIS system, installed on the board of the plane AN-2: 1 - light detectors block; 2 - gyro-platform PAV-20

3 - workstation PC; 4 - keyboard; 5 - monitor PC

Съемки велись с высот 1000, 700, 600 и 300 м. Площадные съемки проведены в результате полета по параллельным маршрутам методом «параллельное галсирование» с высоты 1000 м. Время полета составило 1 час 50 минут. В результате летных испытаний ЭО «АВИС» показал устойчивость к воздействию механических нагрузок при взлете и посадке самолета АН-2 с грунтового аэродрома.

В ходе лётных испытаний авиационной системы «АВИС» была осуществлена проверка работы системы с использованием программного комплекса управления. Программный комплекс продемонстрировал устойчивую работу. Ввиду использования при разработке оптических систем матричного приемника DALSA FTF5066M совместно с объективом
HASSELBLAD HC 2.8/80 особое внимание уделялось именно работе этим модулям.

В результате испытаний данное сочетание матричного приемника и объектива продемонстрировало высокую разрешающую способность и динамический диапазон, позволяющие использовать данный прибор как в качестве автономной регистрирующей камеры высокого разрешения, так и в качестве одного из каналов спектрозонального прибора, поскольку динамический диапазон и чувствительность применённого сенсора позволяют использовать оптические фильтры с различными спектральными диапазонами пропускания.

\section{5. Заключение}

По результатам обработки и анализа данных съемок:

- построены трассовые (линейные) и площадные мозаики районов съемок;

- получены твердые копии спектрозональных и тепловых изображений районов съемок;

- проведены оценки точности определения площадей в видимом и ИК диапазоне (рис. 10-13).

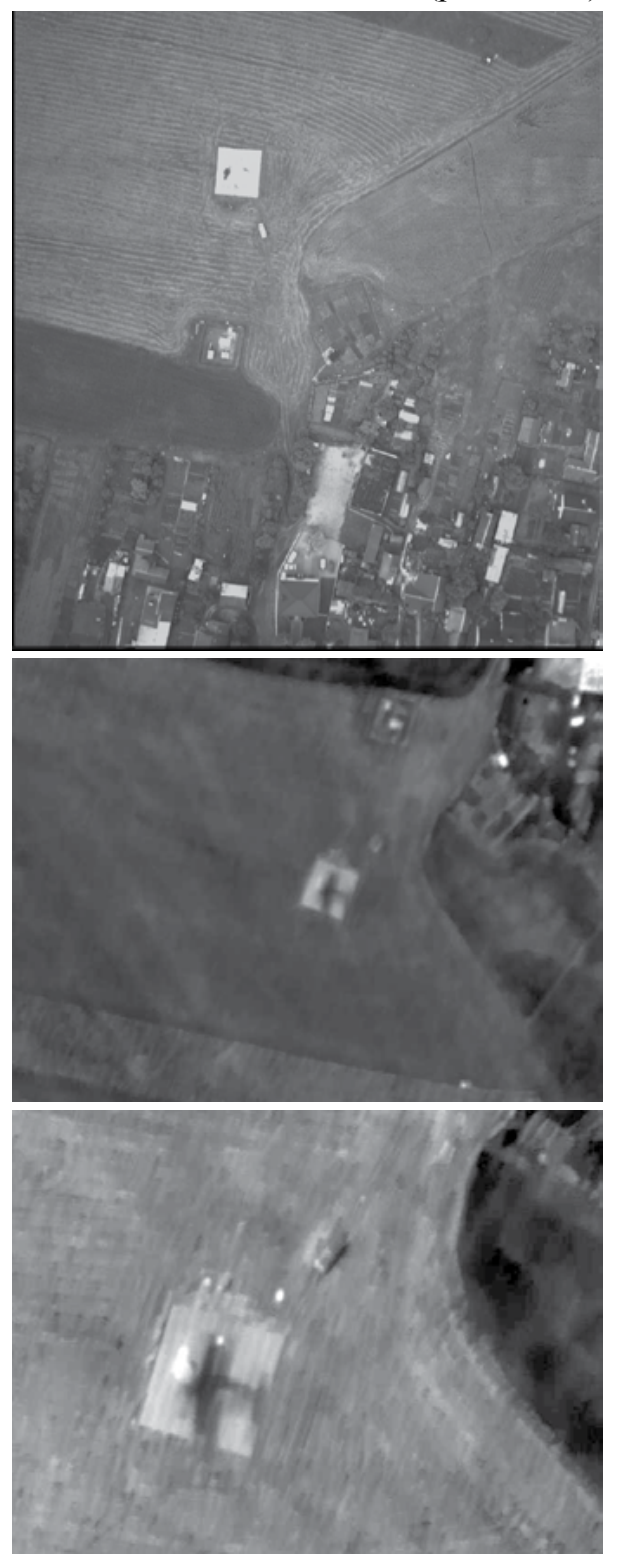

Рис.10. Результаты съёмок МСВ и МИК БОД АВИС Fig. 10. Results of the survey MSVS and MISC BOS AVIS 

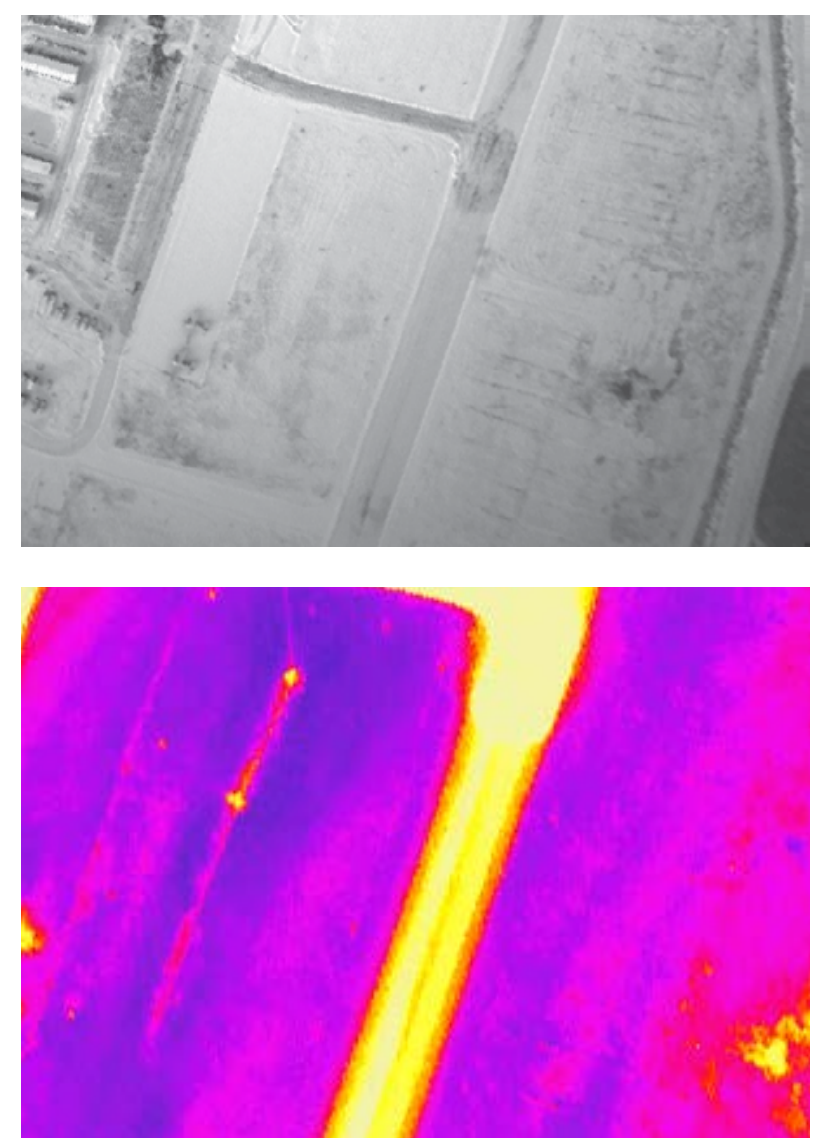

Рис. 11. Результаты съёмок в видимом и тепловом диапазоне длин волн

Fig. 11. Results of the surveys in the visible and thermal wave band

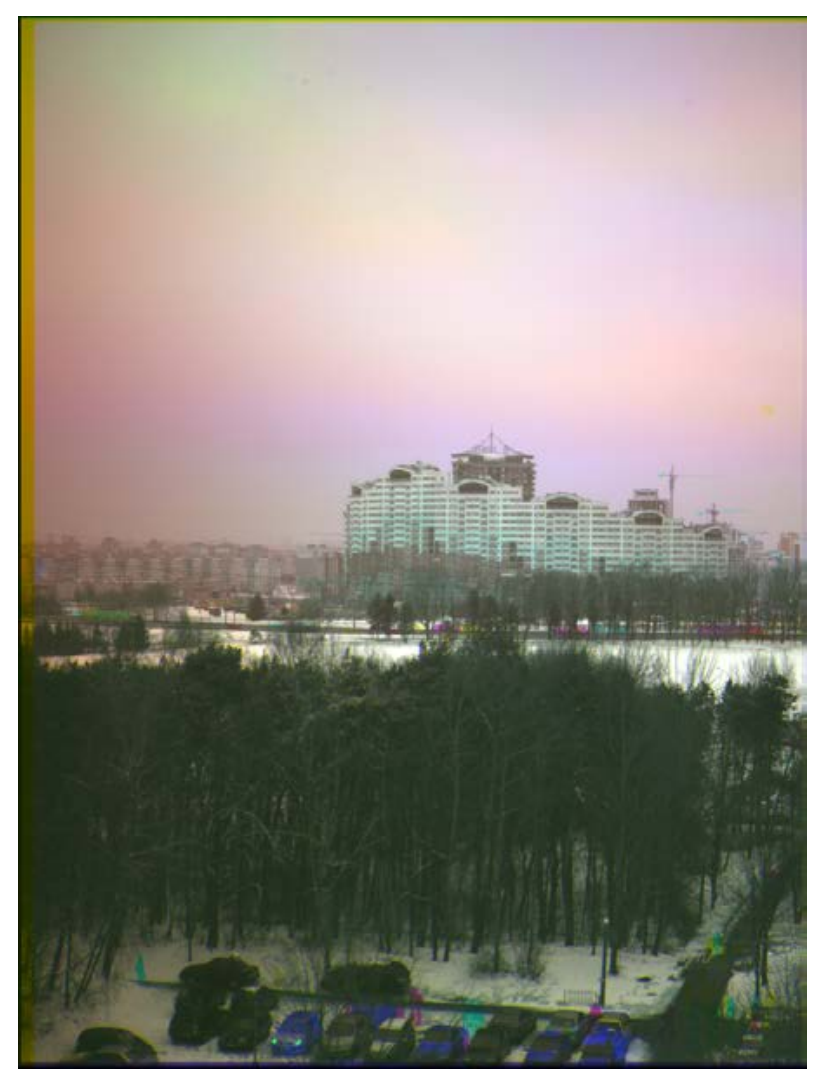

Рис. 12. Спектрозональная съёмка в статическом режиме Fig. 12. The spectrozonal survey under static conditions

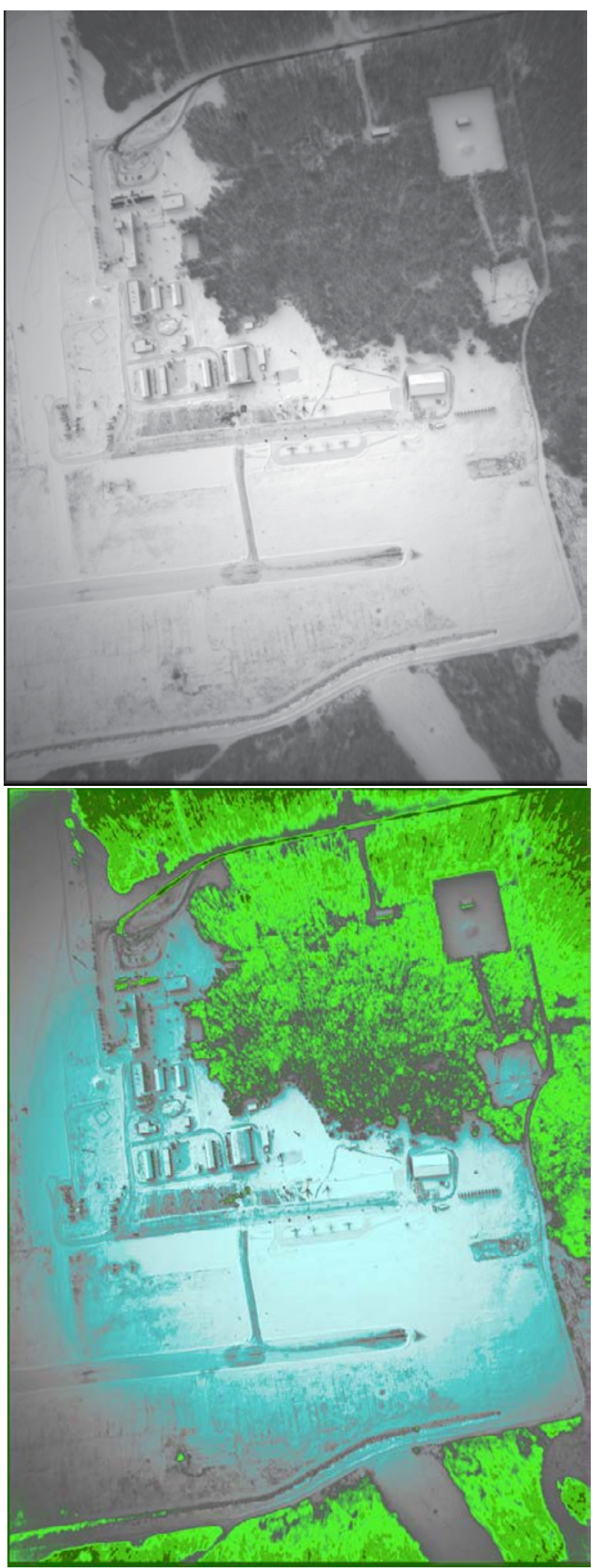

Рис.13. Результаты обработки изображений камер МСВ высокого пространственного разрешения

Fig. 13. The results of the cameras` picture processing MSVS with high spatial resolution 


\section{Литература}

1. Beliaev, B.I. Opticheskoe distantcionnoe zondirovanie, v: B.I. Beliaev, L.V. Katkovskii. - Minsk: BGU, 2006. - 455 s.

2. Bespilotnye letatelnyie apparaty: primenenie $\mathrm{v}$ tceliakh aerofotosemki dlia kartografirovaniia [elektronnyi resurs]. - Rezhim dostupa: http://shhshhshh.racurs.ru/?page=681. - Data dostupa: 15.04.2012.

3. Semka i obrabotka izobrazhenii aviacionnoi sistemy kontrolia chrezvychainykh situacii / B.I. Beliaev [i dr.], v: Zhurn. prikl. Spektroskopii. - 1998. - T. 65. - № 2. - S. 128-131.

4. Pribory i metody aerokosmicheskogo distantcionnogo zondirovaniia prirodnykh obektov / B.I. Beliaev [i dr.] // Zhurn. prikl. Spektroskopii. - 2000. - T. 67. - № 4. - S. 141-152.

5. Katkovskii, L.V. Primenenie aviatcionnoi sistemy kontrolia ChS dlia otcenki pozharnoi opasnosti lesov, obnaruzheniia pozharov i otcenki ikh posledstvii. / L.V. Katkovskii // Doklady BGUIR. - 2010 g. - № 6 (52). - S. 5-13.

6. Semka i obrabotka izobrazhenii aviatcionnoi sistemy kontrolia chrezvychainykh situacii, v: B.I. Beliaev [i dr.] // Kosmichna nauka i tehnologiia. - 2010. - T. 6. - № 2. - S. 41-45.

7. Perspektivy razvitiia tekhnicheskikh sredstv distantcionnogo zondirovaniia Zemli dlia monitoringa chrezvychainykh situacii / A.S. Sizikov [i dr.] // Zhurn. Chrezvychainye situatcii: preduprezhdenie i likvidatciia. - 2012. - № 1 (31). - S. 20-36.

8. Beliaev, B.I. Apparatura distantcionnoi spektrometrii / Beliaev B.I. [i dr.] // Spektroskopiia plazmy i prirodnykh obektov / pod. red. V.I. Arkhipenko, V.S. Burakova, A.F. Cherniavskogo. - Minsk: Belorusskaia nauka, 2007. - Gl. 6. S. 305349 (488 s.).

9. Beliaev, B.I. Sozdanie aviatcionnoi spektrozonalnoi sistemy «AVIS» dlia aerokosmicheskogo monitoringa territorii / Beliaev B.I. [i dr.] // Prikladnyie problemy optiki, informatiki, radiofiziki i fiziki kondensirovannogo sostoianiia: materialy Mezhdunar. nauch.-prakt. konf., posvashchennoi 40-letiiu NIIPFP im. A.N. Sevchenko BGU, 28 fevralia 2011 g. / NIIPFP im. A.N. Sevchenko BGU; red. kol.: V.I. Popechic [i dr.]. - Minsk 2011. S. 1314.

10. Evraziiskii patent № 013800. Aviatcionnyi opticheskii kompleks vysokogo prostranstvennogo i spektralnogo razresheniia s avtomaticheskim adaptivnym upravleniem / Beliaev B.I., Katkovskii L.V., Hvalei S.V. - № 200900899; zaiavl. 08.04.2009 g.; opubl. 30.06.2010 g.

11. Spektroradiometr MS-14 dlia bloka opticheskikh datchikov aviatcionnoi sistemy «AVIS». / Krot Iu.A., Beljaev Iu.V., Kkomicevich A.D., Domaratckii A.V. // Priborostroenie-2011: materialy 4-j Mezhdunar. nauch.-prakt. konf., Minsk, BNTU, 1618 noiabria 2011 g. / BNTU; red. kol.: O.K. Gusev [i dr.]. - Minsk, 2011. S. 100101.
Беляев Борис Илларионович, доктор физико-математических наук, профессор, заведующий отделом аэрокосмических исследований Научно-исследовательского учреждения «Институт прикладных физических проблем имени А.Н. Севченко» Белорусского государственного университета, г. Минск, Республика Беларусь.

Сосенко Виктор Андреевич, кандидат технических наук, заведующий лабораторией оптико-электронных систем Научно-исследовательского учреждения «Институт прикладных физических проблем имени А.Н. Севченко» Белорусского государственного университета, г. Минск, Республика Беларусь.

Чумаков Алексей Викторович, старший научный сотрудник лаборатории оптико-физических измерений Научно-исследовательского учреждения «Институт прикладных физических проблем имени А.Н. Севченко» Белорусского государственного университета, г. Минск, Республика Беларусь.

Беляев Юрий Владимирович, кандидат технических наук заведующий лабораторией оптико-физических измерений, Научно-исследовательского учреждения «Институт прикладных физических проблем имени А.Н. Севченко» Белорусского государственного университета, г. Минск, Республика Беларусь.

Сизиков Алексей Сергеевич, начальник оргнизационно-аналитического отдела Учреждения «Научно-исследовательский институт пожарной безопасности и проблем чрезвычайных ситуаций» МЧС Республики Беларусь, г. Минск. 